Article

\title{
The Effect of Electrolytes on the Photodegradation Kinetics of Caffeine
}

\author{
Pedro M. Rendel ${ }^{1, *}$ and Giora Rytwo ${ }^{1,2}$ (D) \\ 1 Environmental Physical Chemistry Laboratory, MIGAL, Galilee Research Institute, \\ Kiryat Shmona 1101600, Israel; giorarytwo@gmail.com \\ 2 Department of Environmental Sciences, Tel-Hai College, Upper Galilee 1220800, Israel \\ * Correspondence: p.rendel@gns.cri.nz or rendel.rendel@gmail.com
}

Received: 23 April 2020; Accepted: 4 June 2020; Published: 8 June 2020

\begin{abstract}
Unsuccessfully treated by the existing wastewater-treatment processes, caffeine concentrations in wastewater effluents and natural reservoirs are constantly rising. Photodegradation treatment processes are drawing much attention due to their potential to oxidize and remove such, and similar contaminating compounds from treated waters. In continuation to our previous work on the photodegradation kinetics of caffeine in water by $\mathrm{UV} / \mathrm{H}_{2} \mathrm{O}_{2}$ and $\mathrm{UV} / \mathrm{TiO}_{2}$, this work evaluates the influence of various electrolytes, including $\mathrm{NaCl}, \mathrm{KCl}, \mathrm{MgCl}_{2}, \mathrm{NaBr}$, and $\mathrm{KBr}$, on the kinetics of the $\mathrm{UV} / \mathrm{H}_{2} \mathrm{O}_{2}$ photodegradation of caffeine, aiming at estimating the efficiency of the method in more complex water systems. Results show that the efficiency of the $\mathrm{UV} / \mathrm{H}_{2} \mathrm{O}_{2}$ photodegradation reactions is strongly affected by ionic strength and the presence of electrolytes in the solution. While chloride electrolytes were shown to optimize or reduce the process efficiency pending on their concentration. The sole presence of $\mathrm{NaBr}$ and $\mathrm{KBr}$ shows an immediate reduction in the efficiency of the photodegradation. Empirical apparent-rate-coefficients and curves describing the effect of the different electrolytes on the photodegradation kinetics of caffeine are presented.
\end{abstract}

Keywords: photodegradation; kinetics; caffeine; hydrogen peroxide; electrolytes; wastewater

\section{Introduction}

Caffeine is a naturally occurring alkaloid compound widely consumed by the world's population, with an estimated average daily per capita consumption of about $320 \mathrm{mg} \mathrm{day}^{-1}$ [1]. Thus, it is widely identified in seawater, lakes, and aquifers around the globe [2-5], consequently rising concerns regarding its potential impact on natural ecosystems, as well as on agriculture and aquaculture. Such concerns intensify in arid countries where potable desalinated water is regularly consumed, and wastewaters are widely recycled for agriculture use [6].

With the wide recognition of caffeine and other pharmaceutical and personal care products (PPCPs) as emerging contaminants in the aquatic environment [4,7-9], there is an increasing demand to incorporate innovative and complementary water-treatment technologies in municipal wastewater-treatment facilities, in order to reduce the presence of emerging contaminants from the treated effluents [10-12]. Thus, a comprehensive evaluation of the photodegradation kinetics of such contaminants and the possible effect of other constituents in the solution is crucial for the optimization and scale-up of new emerging technologies.

Advanced oxidation processes (AOP) are defined as "those which involve the generation of hydroxyl radicals in sufficient quantity to affect water purification" [13]. AOPs include several catalytic or non-catalytic processes that take advantage of the high oxidizing capacity of such radicals, regardless of how this radical is generated [9]. Research on AOP processes increases constantly [14]. Many AOP processes and technologies are being developed and evaluated to tackle the efficient removal of 
pollutants with the minimum formation of hazardous byproducts [15-20]. In our previous study [21], we experimentally evaluated the degradation kinetics of pure caffeine solutions by $\mathrm{UV} / \mathrm{H}_{2} \mathrm{O}_{2}$ means and established new empirical and theoretical rate laws that describe the degradation kinetics at various UV-C doses (1.9-15.2 $\left.\mathrm{mJ} \mathrm{cm}^{-2} \mathrm{~s}^{-1}, \lambda=254 \mathrm{~nm}\right)$.

Despite great advances in the field, there are rising concerns regarding the efficiency and ability of AOP processes in general, and $\mathrm{UV} / \mathrm{H}_{2} \mathrm{O}_{2}$ photodegradation methods and technologies to cope with large-scale water treatments that include solutions like brines, seawater and common wastewater. These solutions may challenge degradation technologies as they include inorganic salts, large organic loads, and solid particles, which may significantly change the way degradation reactions occur [22-27]. For example, it was shown that chloride, nitrate, perchlorate, and sulfate ions considerably influence the oxidation of organic compounds by Fenton's process performed in the dark [28]. Furthermore, AOP processes might yield to the formation of dangerous halogenated compounds [29]. Thus, such solutions are mostly avoided as their complexity may impose technical challenges as well as barriers in the interpretation of experimental results. Therefore, a more gradually complexation of the experimental solutions may bridge up the gap.

Aiming to estimate the efficiency of the $\mathrm{UV} / \mathrm{H}_{2} \mathrm{O}_{2}$ photodegradation method in more complex water systems, we expanded our experimental work by introducing various electrolytes into the caffeine solution. The photodegradation kinetics of caffeine in solutions containing different concentrations of $\mathrm{NaCl}, \mathrm{KCl}, \mathrm{MgCl}_{2}, \mathrm{NaBr}$, and $\mathrm{KBr}$ were evaluated. The finding of this work may be used as a preliminary guideline for future research and the evaluation of $\mathrm{UV} / \mathrm{H}_{2} \mathrm{O}_{2}$ treatments in more complex solutions.

\section{Results and Discussion}

\subsection{Caffeine Photodegradation in the Presence of $\mathrm{NaCl}, \mathrm{KCl}$ and $\mathrm{MgCl}_{2}$ Electrolytes}

The photodegradation of caffeine as a function of $\mathrm{NaCl}, \mathrm{KCl}$, and $\mathrm{MgCl}_{2}$ concentration is presented in Figure 1. The red marked plot in all panels shows the experimental results of an experiment without electrolytes (further referred to as "base-line"), plots obtained above and below the "base-line", show to have slower or faster kinetics respectively. Note that not all the experimental results are plotted in Figure 1; since results in the range of $1-100 \mathrm{Mm} \mathrm{NaCl}$ and $1-50 \mathrm{mM} \mathrm{KCl}$ tend to have similar rate coefficients (within uncertainty), their results overlap and therefore, are represented by a single representative experiment in each plot. The experiments show a removal rate of $\sim 80 \%-95 \%$ (further degradation was not evaluated due to analytical limitations). The photodegradation trend fits very well with pseudo-zero-order kinetics (Appendix A) as shown by the linear decrease in the relative concentration $A$ with time (Equation (A1)). Compared to the "base-line", the apparent rate coefficient $k_{a p p}$ in experiments with very low electrolytes concentrations $(<50 \mathrm{mM}$ for $\mathrm{KCl}$ and $<100 \mathrm{mM}$ for $\mathrm{NaCl}$ ) appears to be stable (within uncertainties) with a slightly higher efficiency increases as it can be measured by the decrease in half-life time (as seen in Figure 1) from about 8 to 5-7 min. Each rate coefficient shows an average increase of 31\%,27\%, and 39\% respectively (Figure 2), whereas, in experiments with higher concentrations, it shows to follow a logarithmic decline. Consequently, in those experiments $(>0.5 \mathrm{M}$ of $\mathrm{NaCl}$ and $\mathrm{KCl}$ ), the apparent rate coefficient decreases below the "base-line" resulting in a slower reaction rate. Half-life time increases up to $15 \mathrm{~min}$ for $\mathrm{NaCl}$ and even $20 \mathrm{~min}$ for $\mathrm{KCl}$ (Figure 1). An exception was obtained in experiments with $\mathrm{MgCl}_{2}$, where reaction rates stayed above the "base-line" at concentrations of up to $0.5 \mathrm{M}$ (Figure 3), which was the maximum concentration tested for that electrolyte. Note that due to a lack of sufficient data, the regression of the $\mathrm{MgCl}_{2}$ experiments is only an approximation, and no equation is provided. 


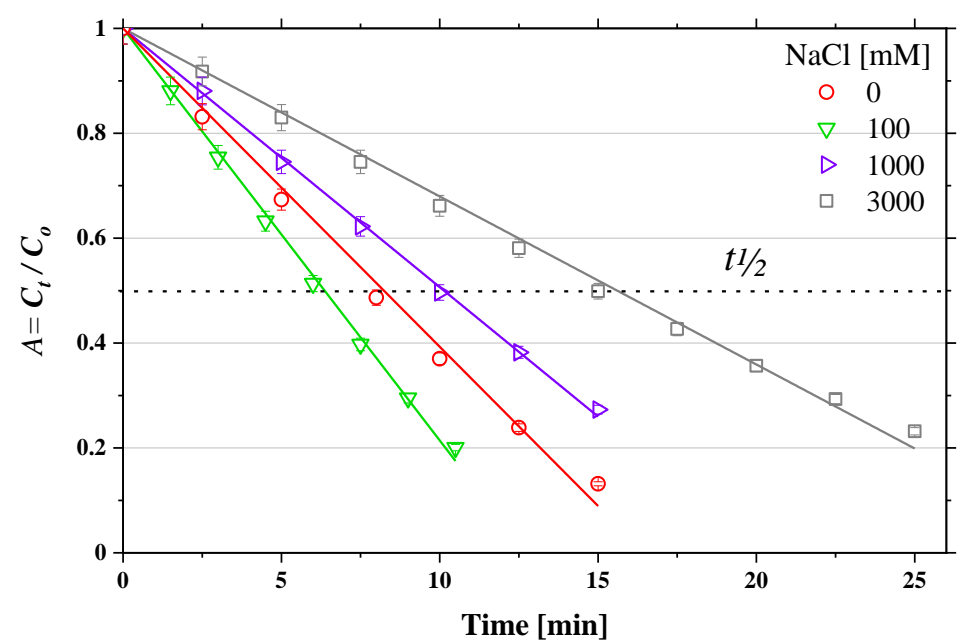

(a)

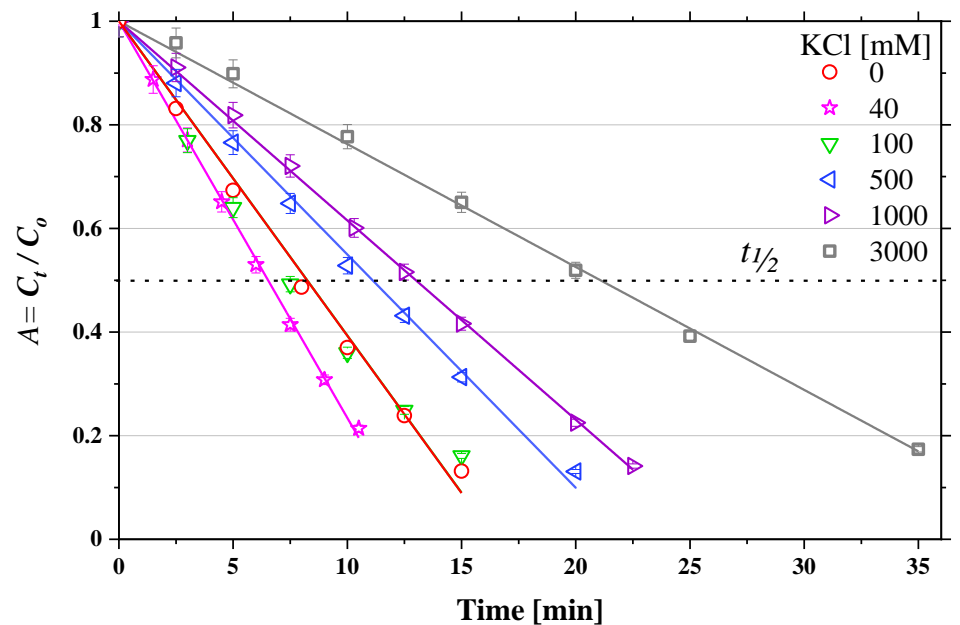

(b)

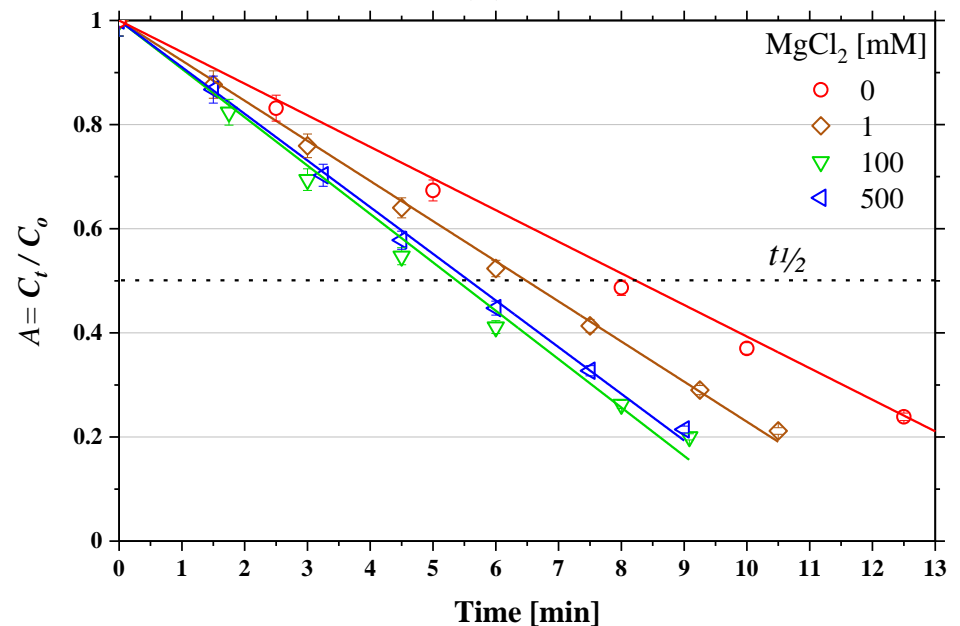

(c)

Figure 1. Degradation of caffeine as a function of time, at various $\mathrm{NaCl}(\mathbf{a}), \mathrm{KCl}(\mathbf{b})$, and $\mathrm{MgCl}_{2}$ (c) concentrations. Plots were evaluated using a pseudo-zero-order kinetic model. 


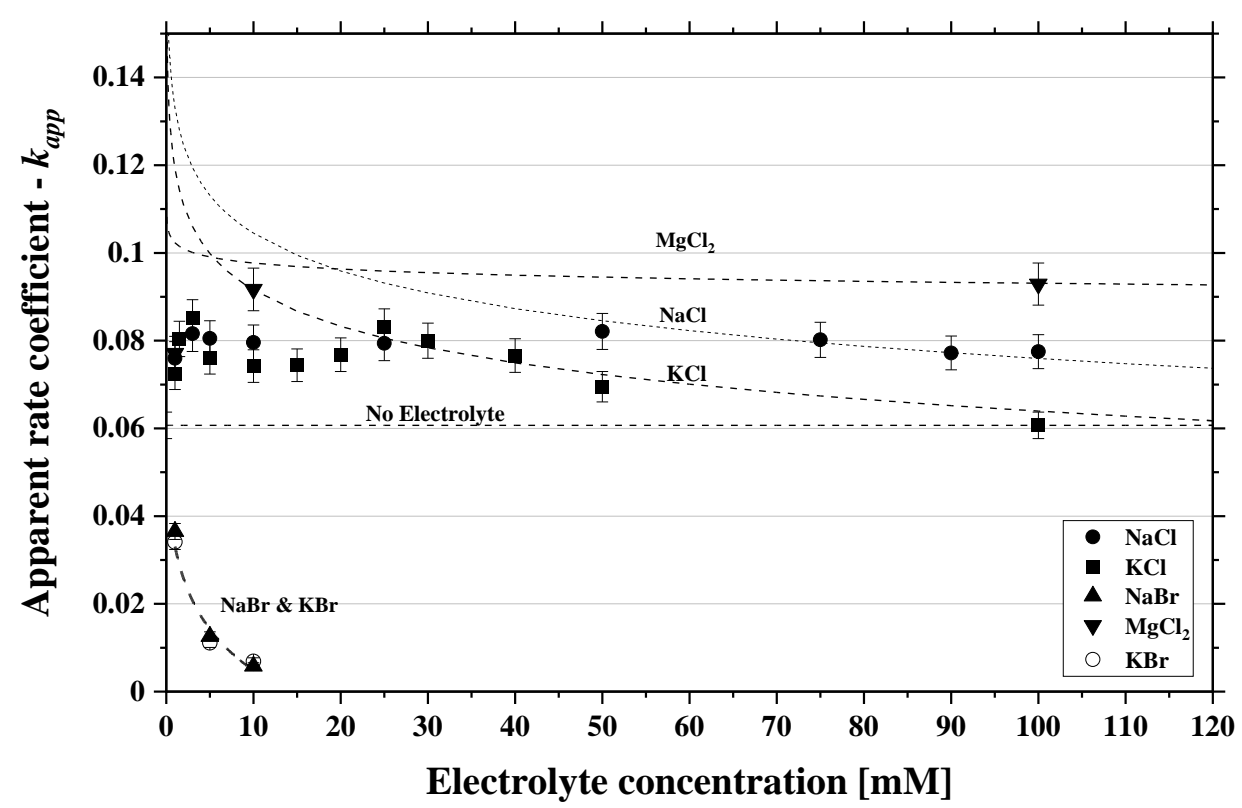

Figure 2. Apparent rate coefficients $\left(k_{a p p}\right)$ as a function of low electrolytes concentrations $(<120 \mathrm{mM})$. (electrolytes are represented by different symbols). Dashed plots represent a logarithmic regression fitting as described by the equations in Figure 2.

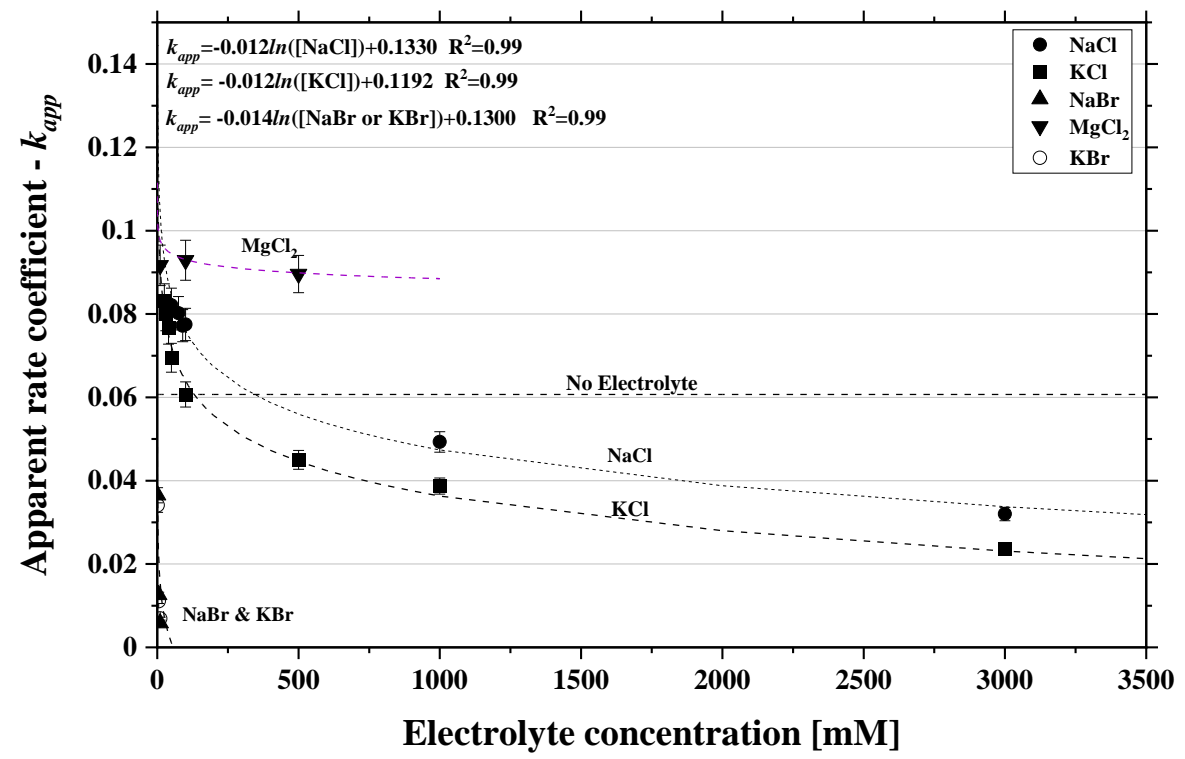

Figure 3. Apparent rate coefficients $\left(k_{a p p}\right)$ as a function of electrolyte concentration (electrolytes are represented by different symbols). Dashed plots represent a logarithmic regression fitting as described by the equations inside the figure.

The improved photodegradation at low concentrations of sodium and potassium chloride, accompanied by a decrease in efficiency at higher concentrations correlate with other recent findings that reported photodegradation rates in the presence of low concentrations of electrolytes [24-26]. $\mathrm{MgCl}_{2}$ behaves differently, with improved efficiency at $0.1 \mathrm{M}$ remaining stable at $0.5 \mathrm{M}$.

Lanzafame et al. (2017) reported a higher photodegradation rate while photodegrading methyl-anthranilate in the presence of a low concentration of $\mathrm{NaCl}(0.1 \mathrm{M})$ and suggested a possible explanation to these phenomena, based on the affinity of chloride to accelerate $\mathrm{UV} / \mathrm{H}_{2} \mathrm{O}_{2}$ 
photodegradation reactions by scavenging $\cdot \mathrm{HO}$ radicals and yielding "more reactive" $\mathrm{Cl}_{2}{ }^{-}$radicals as described in the following reaction path (Equations (1)-(3)) [24]:

$$
\begin{gathered}
\mathrm{HO}+\mathrm{Cl}^{-} \leftrightarrow \mathrm{HOCl}^{-}\left[\mathrm{K}_{\mathrm{eq}, 1}=0.70 \mathrm{M}^{-1}\right], \\
\mathrm{HOCl}^{-} \cdot+\mathrm{H}^{+} \leftrightarrow \mathrm{H}_{2} \mathrm{O}+\mathrm{Cl} \cdot\left[\mathrm{K}_{\mathrm{eq}, 2}=1.6 \times 10^{7} \mathrm{M}^{-1}\right], \\
\mathrm{Cl} \cdot+\mathrm{Cl}^{-} \leftrightarrow \mathrm{Cl}_{2}{ }^{-}\left[\mathrm{K}_{\mathrm{eq}, 3}=1.9 \times 10^{5} \mathrm{M}^{-1}\right] .
\end{gathered}
$$

It should be taken into account that the suggested mechanism by Lanzafame et al., (2017) reduces the concentration of the hydroxyl radicals in the solution (i.e., $\cdot \mathrm{HO}$ ), therefore occasionally it might reduce the efficiency of the process if the product of the process $\left(\mathrm{Cl}_{2}{ }^{-}\right)$results to be less efficient in the degradation of the tested compound. However, the mentioned researchers deduced that the product's degradation efficiency is larger than that of $\cdot \mathrm{HO}$.

Despite the possible positive effect $\mathrm{Cl}^{-}$may have on the photodegradation rates, slower rates were measured in the experiments with high chloride concentrations $(0.5,1$, and $3 \mathrm{M})$. In order to determine the optimal concentration of electrolyte for maximum efficiency and minimum half-life time, a continuation study including additional experimental data-points in the range of $0.1-1 \mathrm{M}$ of chloride salts is needed. Such a study might help to elucidate the full degradation path.

As a preliminary assumption, we hypothesize that the positive influence on the photodegradation rates attributed to the newly formed chlorine radicals might be hindered at high electrolyte concentrations experiments $(>0.5 \mathrm{M})$ by other possible influences related to the very high ionic strength. At such conditions, the activity coefficient of the species in solution reaches relatively high values. For example, the activity coefficients of $\mathrm{Cl}^{-}$and $\mathrm{Na}^{+}$increase from 0.077 to 0.644 and from 0.079 to 0.781 when solution concentrations increase from 0.1 and $1 \mathrm{M}$ for $\mathrm{NaCl}$ and $\mathrm{KCl}$ respectively (calculated using Phreeqc v.3, USGS, USA [30]). Therefore, the possible effect of such changes on the overall chemical processes, including photodegradation cannot be ruled out.

The possible influence of the different cations is also unclear. By comparing experiments with concentrations higher than $100 \mathrm{mM}$ of $\mathrm{KCl}$ and $\mathrm{NaCl}$, similar trends can be seen but at different degradation rates (Figure 3). On the other hand, $\mathrm{Mg}^{2+}$ has a much stable behavior than the monovalent cations, even though each mole of $\mathrm{MgCl}_{2}$ has twice as moles of $\mathrm{Cl}^{-}$than $\mathrm{Mg}^{2+}$. In general, it seems that $\mathrm{Mg}^{2+}$ yields a completely different effect from the observed with $\mathrm{Na}^{+}$or $\mathrm{K}^{+}$. It can also be seen that $\mathrm{Mg}^{2+}$ tends to enhance the reaction rate and lower the time required for degradation (see Figure 1c). Such differences might be related to specific interactions or the different hydration shells, however, further studies are required in order to fully elucidate the possible effect of each specific cation $\left(\mathrm{K}^{+}, \mathrm{Na}^{+}\right.$ and, $\mathrm{Mg}^{2+}$ ) on photodegradation kinetics, and research on the full degradation mechanisms is needed.

\subsection{Caffeine Photodegradation in the Presence of $\mathrm{KBr}$ and $\mathrm{NaBr}$ Electrolytes}

The presence $\mathrm{KBr}$ and $\mathrm{NaBr}$ electrolytes had a strong impact on the photodegradation rates of caffeine, as the apparent rate coefficient decreased by more than $40 \%$ in the presence of a very low concentration of roughly $1 \mathrm{mM}$ of $\mathrm{KBr}$ or $\mathrm{NaBr}$ (Figure 2). Both bromide salts follow a similar degradation trend, implying that the $\mathrm{Br}^{-}$anion is the one responsible for the observed effect. Similar to the other discussed electrolytes, the apparent rate coefficient to decreased logarithmically as the concentration increased. The apparent rate coefficient as a function of a low-range $\mathrm{NaBr}$ concentration $(<10 \mathrm{mM})$ in the presence of different $\mathrm{H}_{2} \mathrm{O}_{2}$ concentrations is shown in Figures 4 and 5. As previously seen, the results show a significant decrease in the photodegradation rate of caffeine, while $\mathrm{NaBr}$ is introduced into the solution. 


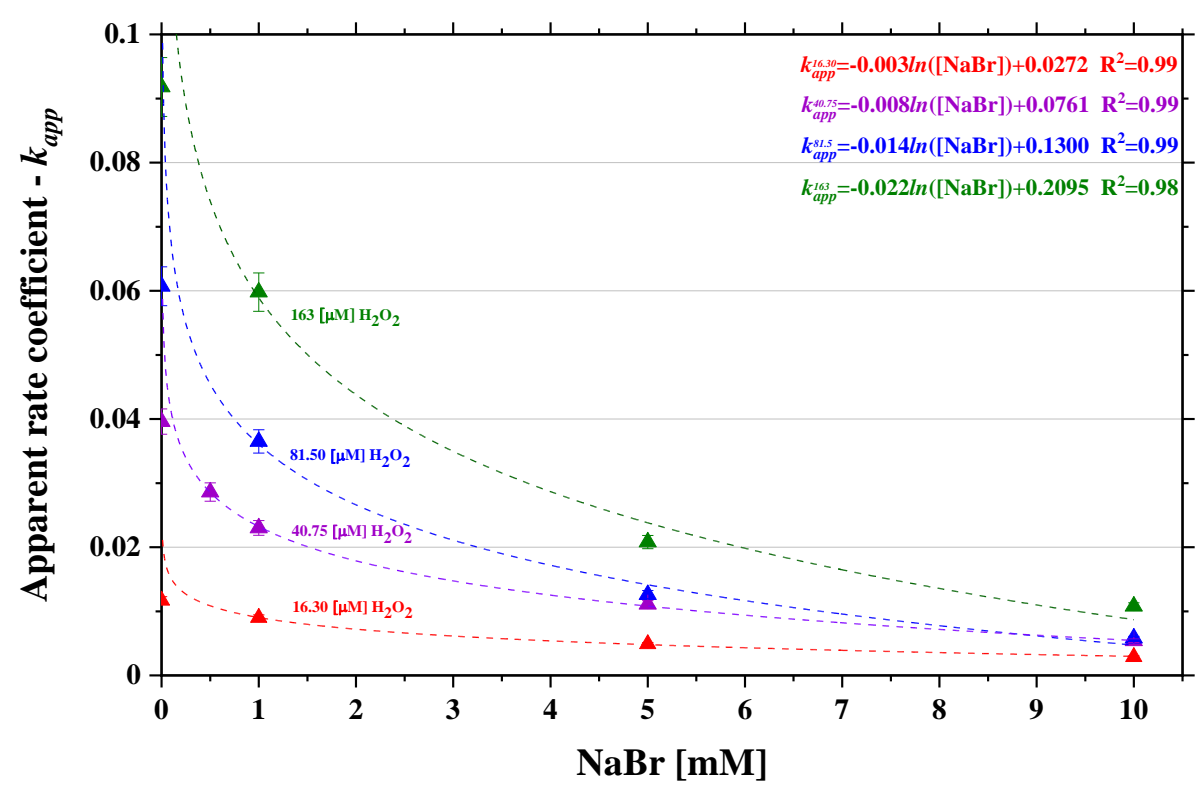

Figure 4. Apparent rate coefficients $\left(k_{\text {app }}\right)$ as a function of $\mathrm{NaBr}$ concentrations, in the presence of different $\mathrm{H}_{2} \mathrm{O}_{2}$ concentrations in $\mu \mathrm{M}(16.3,40.75,81.5$ and 163 represented by the different colors: red, purple, blue and green respectively). Dashed plots represent a logarithmic regression fitting as described by the equations.

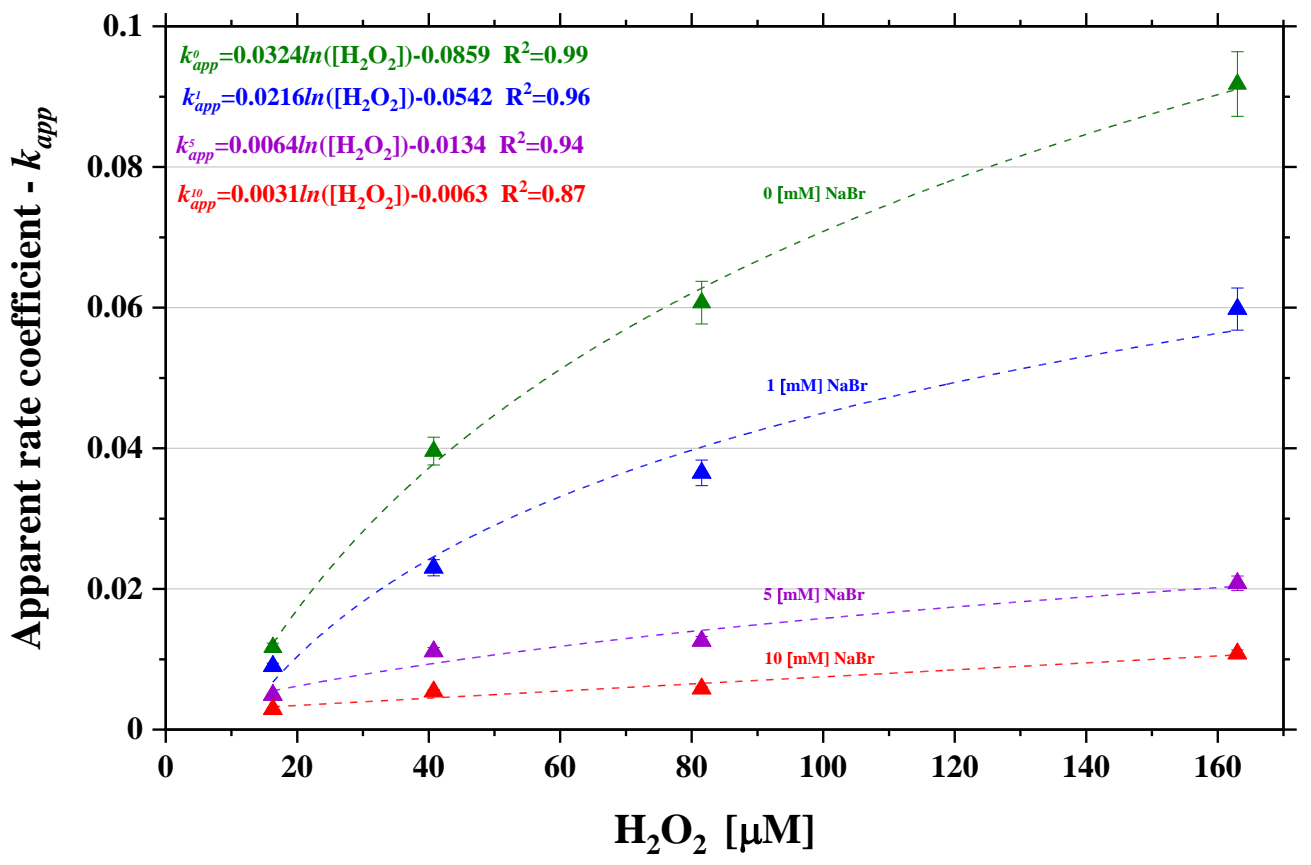

Figure 5. Apparent rate coefficients $\left(k_{a p p}\right)$ as a function of $\mathrm{H}_{2} \mathrm{O}_{2}$ concentrations, in the presence of different $\mathrm{NaBr}$ concentrations in $\mathrm{mM}(10,5,1$, and 0 represented by the different colors: red, purple, blue and green respectively). Dashed plots represent a logarithmic regression fitting as described by the equations.

This sharp decrease in the photodegradation rate can be explained by two $\mathrm{H}_{2} \mathrm{O}_{2}$ competing decomposition-reactions which take place simultaneously in the solution: (a) photocatalytic decomposition, which creates $\cdot \mathrm{OH}$ radicals by decomposing $\mathrm{H}_{2} \mathrm{O}_{2}$ with $\mathrm{UVC}$ radiation (Equation (4)); 
(b) $\mathrm{Br}^{-}$catalysis, on which $\mathrm{Br}^{-}$acts as a catalyst in the decomposition reaction of $\mathrm{H}_{2} \mathrm{O}_{2}$ in the solution, and turns $\mathrm{H}_{2} \mathrm{O}_{2}$ into $\mathrm{H}_{2} \mathrm{O}$ and $\mathrm{O}_{2}$ (Equations (5) and (6)) [31].

$$
\begin{gathered}
\mathrm{H}_{2} \mathrm{O}_{2}+h v \rightarrow 2 \cdot \mathrm{OH} \\
\mathrm{H}_{2} \mathrm{O}_{2}+2 \mathrm{Br}^{-}+2 \mathrm{H}^{+} \rightarrow \mathrm{Br}_{2}+2 \mathrm{H}_{2} \mathrm{O} \\
\mathrm{Br}_{2}+\mathrm{H}_{2} \mathrm{O}_{2} \rightarrow 2 \mathrm{Br}^{-}+2 \mathrm{H}^{+}+\mathrm{O}_{2} .
\end{gathered}
$$

The $\mathrm{Br}^{-}$catalytic reaction appears to have much faster kinetics than the photocatalytic reaction has, resulting in low concentrations of $\cdot \mathrm{OH}$ radicals, which are an essential component in any degradation process. Therefore, the introduction of any $\mathrm{Br}^{-}$into the system may eventually prevent the photocatalytic degradation reaction to take place as expected.

Further reinforcement to this conclusion can be seen in Figure 5 wherein experiments with higher concentrations of $\mathrm{H}_{2} \mathrm{O}_{2}$ have higher degradation efficiency, proving that the lack of $\cdot \mathrm{OH}$ radicals may be the reason for the reduction of the photodegradation efficiency.

Apparently, $\mathrm{pH}$ should have a direct impact on the $\mathrm{H}_{2} \mathrm{O}_{2}$ decomposition catalyzed by $\mathrm{Br}^{-}$, since protons react according to Equation (5) but are a product of Equation (6); their total concentration remains unchanged and their influence is mainly on the rate of decomposition of $\mathrm{H}_{2} \mathrm{O}_{2}$ that increases at very low $\mathrm{pH}$ values [31]. However, it remains significant even at neutral $\mathrm{pH}$ as it is shown in our study.

Figures 4 and 5 present calculated apparent rate coefficients for Equation (A1), according to a pseudo-zero-order process, since such order yields a relatively good fit for all experiments. Table A1 in Appendix $B$ presents the apparent rate coefficients and the empirical equations for each order, and their relative $R^{2}$ fitting parameters.

It can be seen that at high $\mathrm{NaBr}$ concentrations (see Table A2), the fit to pseudo-zero-order decreases and a slightly better fit (in terms of $\mathrm{R}^{2}$ ) to pseudo-first, and even -second-order reaction is observed. We assume that if those slight differences indicate real effects, this might be ascribed to the fact that as bromine concentration increases, the influence on the $\mathrm{H}_{2} \mathrm{O}_{2}$-degradation changes the overall process, making the influence of caffeine concentration more significant. Such changes in the order of the process can only be fully elucidated by finding a full set of elementary steps for the whole process as presented in the past for processes like Michaelis-Menten, Lindeman-Hindelwood, or even our previous study [21].

\section{Materials and Methods}

The degradation kinetics of caffeine in the presence of the different electrolytes was evaluated by performing a series of batch experiments in a mini photochemical chamber reactor following the same procedure previously described at Rendel and Rytwo, (2020) [21]. Electrolyte solutions with concentrations ranging from $1.0 \mathrm{mM}$ to $3.0 \mathrm{M}$ were prepared by mixing their corresponding salts (Sigma-Aldrich, St. Louis, MI, USA) with deionized water. Final solutions containing both caffeine and the different electrolytes were exposed to UV-C radiation $(254 \mathrm{~nm}$ wavelength and intensity of $15.2 \mathrm{~mJ}$ $\left.\mathrm{cm}^{-2} \mathrm{~s}^{-1}\right)$ in the presence of $81.5 \mu \mathrm{mol} \mathrm{L}^{-1}\left(2.77 \mathrm{mg} \mathrm{L}^{-1}\right) \mathrm{H}_{2} \mathrm{O}_{2}$ oxidation agent (Merck, Darmstadt, Germany). An exception was done in the experiments with $\mathrm{NaBr}$ were $\mathrm{H}_{2} \mathrm{O}_{2}$ concentration varies in the range of $16.3-163 \mu \mathrm{mol} \mathrm{L}^{-1}\left(0.55-5.54 \mathrm{mg} \mathrm{L}^{-1}\right)$. A detailed experimental plan is presented in Table 1. 
Table 1. Experiments and results.

\begin{tabular}{|c|c|c|c|c|}
\hline Exp. \# & Electrolyte Type & $\begin{array}{c}\text { Electrolyte } \\
\text { Concentration } \\
{\left[\mathrm{mmol} \mathrm{L}^{-1}\right]}\end{array}$ & $\begin{array}{c}\mathrm{H}_{2} \mathrm{O}_{2} \\
\text { Concentration } \\
{\left[\mu \mathrm{mol} \mathrm{L}^{-1}\right]}\end{array}$ & $\begin{array}{c}\text { Apparent Rate } \\
\text { Coefficient } k_{a p p} \\
{\left[\mathrm{~min}^{-1}\right]}\end{array}$ \\
\hline 1 & Non,Baseline & 0 & 81.5 & 0.0607 \\
\hline 2 & $\mathrm{NaCl}$ & 1 & 81.5 & 0.0760 \\
\hline 3 & $\mathrm{NaCl}$ & 3 & 81.5 & 0.0816 \\
\hline 4 & $\mathrm{NaCl}$ & 5 & 81.5 & 0.0805 \\
\hline 5 & $\mathrm{NaCl}$ & 10 & 81.5 & 0.0796 \\
\hline 6 & $\mathrm{NaCl}$ & 25 & 81.5 & 0.0794 \\
\hline 7 & $\mathrm{NaCl}$ & 50 & 81.5 & 0.0821 \\
\hline 8 & $\mathrm{NaCl}$ & 75 & 81.5 & 0.0802 \\
\hline 9 & $\mathrm{NaCl}$ & 90 & 81.5 & 0.0772 \\
\hline 10 & $\mathrm{NaCl}$ & 100 & 81.5 & 0.0786 \\
\hline 11 & $\mathrm{NaCl}$ & 1000 & 81.5 & 0.0493 \\
\hline 12 & $\mathrm{NaCl}$ & 3000 & 81.5 & 0.0320 \\
\hline 13 & $\mathrm{KCl}$ & 1 & 81.5 & 0.0725 \\
\hline 14 & $\mathrm{KCl}$ & 1.5 & 81.5 & 0.0804 \\
\hline 15 & $\mathrm{KCl}$ & 3 & 81.5 & 0.0851 \\
\hline 16 & $\mathrm{KCl}$ & 5 & 81.5 & 0.0762 \\
\hline 17 & $\mathrm{KCl}$ & 10 & 81.5 & 0.0742 \\
\hline 18 & $\mathrm{KCl}$ & 15 & 81.5 & 0.0744 \\
\hline 19 & $\mathrm{KCl}$ & 20 & 81.5 & 0.0768 \\
\hline 20 & $\mathrm{KCl}$ & 25 & 81.5 & 0.0831 \\
\hline 21 & $\mathrm{KCl}$ & 30 & 81.5 & 0.0800 \\
\hline 22 & $\mathrm{KCl}$ & 40 & 81.5 & 0.0766 \\
\hline 23 & $\mathrm{KCl}$ & 50 & 81.5 & 0.0695 \\
\hline 24 & $\mathrm{KCl}$ & 100 & 81.5 & 0.0607 \\
\hline 25 & $\mathrm{KCl}$ & 500 & 81.5 & 0.0450 \\
\hline 26 & $\mathrm{KCl}$ & 1000 & 81.5 & 0.0387 \\
\hline 27 & $\mathrm{KCl}$ & 3000 & 81.5 & 0.0237 \\
\hline 28 & $\mathrm{MgCl}_{2}$ & 1 & 81.5 & 0.0771 \\
\hline 29 & $\mathrm{MgCl}_{2}$ & 10 & 81.5 & 0.0917 \\
\hline 30 & $\mathrm{MgCl}_{2}$ & 100 & 81.5 & 0.0929 \\
\hline 31 & $\mathrm{MgCl}_{2}$ & 500 & 81.5 & 0.0896 \\
\hline 32 & $\mathrm{NaBr}$ & 1 & 16.3 & 0.0090 \\
\hline 33 & $\mathrm{NaBr}$ & 5 & 16.3 & 0.0049 \\
\hline 34 & $\mathrm{NaBr}$ & 10 & 16.3 & 0.0029 \\
\hline 35 & $\mathrm{NaBr}$ & 0.5 & 40.75 & 0.0286 \\
\hline 36 & $\mathrm{NaBr}$ & 1 & 40.75 & 0.0230 \\
\hline 37 & $\mathrm{NaBr}$ & 5 & 40.75 & 0.0111 \\
\hline 38 & $\mathrm{NaBr}$ & 10 & 40.75 & 0.0054 \\
\hline 39 & $\mathrm{NaBr}$ & 1 & 81.5 & 0.0365 \\
\hline 40 & $\mathrm{NaBr}$ & 5 & 81.5 & 0.0126 \\
\hline 41 & $\mathrm{NaBr}$ & 10 & 81.5 & 0.0058 \\
\hline 42 & $\mathrm{NaBr}$ & 1 & 163 & 0.0598 \\
\hline 43 & $\mathrm{NaBr}$ & 5 & 163 & 0.0208 \\
\hline 44 & $\mathrm{NaBr}$ & 10 & 163 & 0.0108 \\
\hline 45 & $\mathrm{KBr}$ & 1 & 81.5 & 0.0341 \\
\hline 46 & $\mathrm{KBr}$ & 5 & 81.5 & 0.0111 \\
\hline 47 & $\mathrm{KBr}$ & 10 & 81.5 & 0.0069 \\
\hline
\end{tabular}

All experiments conducted with a caffeine concentration of $19.6 \mathrm{mg} \mathrm{L}^{-1}$, a $5 \%$ uncertainty is estimated for the apparent rate-coefficients.

\section{Experimental Setup}

The degradation reaction was performed in a Rayonet RMR-600 mini photochemical chamber reactor (Southern New England Ultraviolet Company, Branford, CT, USA) and periodically sampled for UV-VIS spectroscopy measurement of caffeine concentration in a 8452A diode array spectrophotometer 
driven by Chemstation 06.03 software (Hewlett Packard Palo Alto, Ca, USA). Following the same protocol detailed described in Reference [21]. The uncertainty of the measurements was estimated at less than $3 \%$.

\section{Summary and Conclusions}

Considering the present constituents in treated waters are crucial to accurately evaluate the efficiency of AOP processes, this study presents an experimental work performed to elucidate the effect of electrolytes on the photocatalytic degradation process, using caffeine as a representative PPCPs substance contaminating the aquatic environment. The experimental work focused on the effect caused by the presence of different concentrations of chloride and bromide electrolytes in caffeine solutions, reacting in a photocatalytic reactor in the presence of $\mathrm{H}_{2} \mathrm{O}_{2}$. As for relatively low chloride electrolytes, the results (Figure 2), show that the apparent rate coefficient (as presented in Equation (A1)) increased, whereas at higher electrolyte concentrations a decrease in $k_{a p p}$ was observed in the presence of monovalent cations, whereas as for a divalent cation $\left(\mathrm{Mg}^{2+}\right)$ this effect was not seen. The results as presented in Figure 3 show good agreement with the regression equations that empirically correlate between the apparent coefficient and the electrolyte concentration. Such kind of empirical curve might be used in combination with pseudo-rate-laws (as Equation (A1)) to deliver an evaluation of photodegradation processes at different electrolyte concentrations in the range of $0.1-3 \mathrm{M}$.

This study provides further evidence on the crucial role electrolytes might have, either in the creation of potential radicals that contribute to the acceleration or inhibition of the degradation reaction (as in $\mathrm{Cl}^{-}$) or in the complete "quenching" of the degradation (as in $\mathrm{Br}^{-}$).

As for the chloride electrolytes, no clear explanation was found for the differences in efficiency as a function of $\mathrm{Cl}^{-}$concentration, although it may be assumed that the overall reduction of the reaction rate at high salt concentrations may be related to effects of the ionic strength on the activity coefficients, to the formation of other species, or the influence of specific cations in the solution matrix, as has been shown in the case of $\mathrm{KCl}$ and $\mathrm{NaCl}$. It can be concluded that waters with up to $100 \mathrm{mM}$ of chloridic electrolytes have a good response to photocatalytic degradation treatments, but a possible reduction in the process efficiency may be found at higher concentrations. On the other hand, $\mathrm{MgCl}_{2}$ has an overall positive effect on the photodegradation reaction rates (Figure 3). If the effect is proven to be real for other cases, this electrolyte may be considered as a potential additive to accelerate photodegradation reactions. However, additional studies are required to indeed fully understand if it is a specific effect of $\mathrm{Mg}^{2+}$ or if other divalent $\left(\mathrm{as} \mathrm{Ca}^{2+}\right)$ or even trivalent $\left(\mathrm{Y}^{3+}, \mathrm{La}^{3+}\right)$ cations act similarly when added as chloride salts.

As mentioned above, for the bromidic electrolytes, measurements show a massive decrease in the reaction rate even at very low electrolyte concentrations, completely interfering with the photodegradation process in the presence of more than $1 \mathrm{mM} \mathrm{Br}^{-}$, as shown in Figure 4 . This could be assumed a priori, considering studies on the fast catalytic degradation of $\mathrm{H}_{2} \mathrm{O}_{2}$ by $\mathrm{Br}^{-}$ions in the solution [31], leading to a reduction in oxidation potential due to the lack of $\cdot \mathrm{OH}$ radicals created by the interaction with the UVC radiation. It can be concluded that even at low concentrations of $\mathrm{Br}^{-}$in solution (either in natural water or in industrial effluents) $\mathrm{UV} / \mathrm{H}_{2} \mathrm{O}_{2}$ degradation processes should be completely avoided.

In summary, this work exhibits an empiric relation between the presence of different electrolytes and their effect on caffeine degradation rates, as well as some preliminary hypotheses on the possible reasons leading to these changes. The presented conclusions, as well as the apparent coefficients equations combined with Equation (A1) pseudo-rate-law, can be used as a preliminary guideline to evaluate the potential effect of dissolved electrolytes in water and effluents' treatments based on $\mathrm{UV} / \mathrm{H}_{2} \mathrm{O}_{2}$ technologies.

Author Contributions: P.M.R., designed and performed the experiments, derived the models and analyzed the data and wrote the manuscript with inputs from G.R., which designed the experimental setup, and supervised the project. All authors have read and agreed to the published version of the manuscript. 
Funding: This research was supported by a MIGAL internal grant.

Acknowledgments: We would like to express our gratitude to J. Borzenko and C. Michaeli for their technical assistance and to the guest editors of this special issue for their consideration, José Rivera-Utrilla, María V. López-Ramón, and Manuel Sánchez-Polo. We would also like to express our gratitude and appreciation for the detailed and enlightening review carried out by the editor and anonymous reviewers.

Conflicts of Interest: The authors declare no conflict of interest.

\section{Appendix A}

\section{Apparent Rate Coefficient Calculations}

Caffeine degradation can be defined by a simple rate law while considering all parameters (e.g., degradation agent concentration, irradiation rate, temperature, etc.) as constant:

$$
v=\frac{d[C]}{d t}=k_{a p p}[C]^{n_{a p p}},
$$

where $v$ is the reaction rate, $k_{a p p}$ is the apparent rate coefficient, $C$ is the caffeine concentration and $n_{a p p}$ is the apparent or "pseudo" reaction order. $n_{a p p}$ can be found empirically and is related to the mechanism by which the process occurs. The term "pseudo" is usually used to acknowledge the fact that all other influencing parameters (degradation agent, temperature, light, etc.) were kept constant, either actually (as in catalysts) or virtually (their initial concentration was so large that the change in concentration was insignificant [32].

To simplify the calculations and allow comparisons between parameters in different reaction mechanisms, the "relative concentration at time $\mathrm{t}^{\text {" }}(A)$ was defined as $C_{t} / C_{0}$ (the ratio of actual to initial concentration); thus $A_{0}=1$. Since $A$ is dimensionless, none of the parameters had concentration units. This is convenient since it yields apparent kinetic coefficients that always have dimensions per time, regardless of the order of the process [16]. Specific rate laws for pseudo zero and first-order kinetics are shown in Appendix B at Rendel and Rytwo, (2020) [21].

\section{Appendix B}

Table A1. Apparent rate coefficients for Equation (A1) at pseudo-zero, -first, and -second-order reaction derived from the $\mathrm{NaBr}-\mathrm{KBr}$ experimental results.

\begin{tabular}{|c|c|c|c|c|c|c|}
\hline \multirow{2}{*}{ Exp. \# } & \multicolumn{6}{|c|}{ Apparent Rate Coefficient $k_{a p p}\left[\min ^{-1}\right]$} \\
\hline & Pseudo-Zero-Order & $\mathbf{R}^{2}$ & Pseudo-First-Order & $\mathbf{R}^{2}$ & Pseudo-Second-Order & $\mathbf{R}^{2}$ \\
\hline 32 & 0.0090 & 0.9374 & 0.0150 & 0.9987 & 0.0288 & 0.9485 \\
\hline 33 & 0.0049 & 0.9347 & 0.0063 & 0.9831 & 0.0084 & 0.9974 \\
\hline 34 & 0.0029 & 0.8980 & 0.0035 & 0.9423 & 0.0050 & 0.9916 \\
\hline 35 & 0.0286 & 0.9914 & 0.0451 & 0.9771 & 0.0799 & 0.8629 \\
\hline 36 & 0.0230 & 0.9902 & 0.0368 & 0.9755 & 0.0669 & 0.8508 \\
\hline 37 & 0.0111 & 0.9626 & 0.0168 & 0.9985 & 0.0283 & 0.9564 \\
\hline 38 & 0.0054 & 0.9307 & 0.0072 & 0.9859 & 0.0098 & 0.9980 \\
\hline 39 & 0.0365 & 0.9936 & 0.0614 & 0.9788 & 0.1320 & 0.8342 \\
\hline 40 & 0.0126 & 0.9318 & 0.0208 & 0.9988 & 0.0392 & 0.9389 \\
\hline 41 & 0.0058 & 0.7668 & 0.0091 & 0.9398 & 0.0157 & 0.9930 \\
\hline 42 & 0.0598 & 0.9919 & 0.0934 & 0.9842 & 0.1625 & 0.8967 \\
\hline 43 & 0.0208 & 0.9630 & 0.0348 & 0.9921 & 0.0784 & 0.8814 \\
\hline 44 & 0.0108 & 0.9194 & 0.0176 & 0.9972 & 0.0340 & 0.9691 \\
\hline 45 & 0.0341 & 0.9906 & 0.0504 & 0.9901 & 0.1009 & 0.8736 \\
\hline 46 & 0.0111 & 0.8709 & 0.0205 & 0.9958 & 0.0467 & 0.9304 \\
\hline 47 & 0.0069 & 0.8704 & 0.0101 & 0.9659 & 0.0159 & 0.9934 \\
\hline
\end{tabular}

An estimated 5\% uncertainty is considered for the presented apparent rate coefficient values. 
Table A2. Equations for the evaluation of the apparent rate coefficients in Equation (A1), assuming pseudo-zero, -first, or -second-order reaction derived from the $\mathrm{NaBr}-\mathrm{KBr}$ experimental results.

\begin{tabular}{|c|c|c|c|c|c|c|}
\hline \multirow[b]{2}{*}{$\mathrm{NaBr}[\mathrm{mM}]$} & \multicolumn{6}{|c|}{ Empirical Curves } \\
\hline & Pseudo-zero-order & $\mathrm{R}^{2}$ & Pseudo-first-order & $\mathrm{R}^{2}$ & Pseudo-second-order & $\mathrm{R}^{2}$ \\
\hline 1 & $\begin{aligned} k_{a p p}= & 0.0216 \ln \left(\left[\mathrm{H}_{2} \mathrm{O}_{2}\right]\right) \\
& -0.0542\end{aligned}$ & 0.96 & $\begin{aligned} k_{a p p}= & 0.0338 \ln \left(\left[\mathrm{H}_{2} \mathrm{O}_{2}\right]\right) \\
& -0.0836\end{aligned}$ & 0.98 & $\begin{aligned} k_{a p p}= & 0.0609 \ln \left(\left[\mathrm{H}_{2} \mathrm{O}_{2}\right]\right) \\
& -0.1461\end{aligned}$ & 0.97 \\
\hline 5 & $\begin{aligned} k_{a p p}= & 0.0064 \ln \left(\left[\mathrm{H}_{2} \mathrm{O}_{2}\right]\right) \\
& -0.0134\end{aligned}$ & 0.94 & $\begin{aligned} k_{a p p}= & 0.0117 \ln \left(\left[\mathrm{H}_{2} \mathrm{O}_{2}\right]\right) \\
& -0.0271\end{aligned}$ & 0.95 & $\begin{aligned} k_{\text {app }}= & 0.0287 \ln \left(\left[\mathrm{H}_{2} \mathrm{O}_{2}\right]\right) \\
& -0.0761\end{aligned}$ & 0.92 \\
\hline 10 & $\begin{aligned} k_{a p p}= & 0.0031 \ln \left(\left[\mathrm{H}_{2} \mathrm{O}_{2}\right]\right) \\
& -0.0063\end{aligned}$ & 0.87 & $\begin{aligned} k_{\text {app }}= & 0.0057 \ln \left(\left[\mathrm{H}_{2} \mathrm{O}_{2}\right]\right) \\
& -0.0135\end{aligned}$ & 0.89 & $\begin{aligned} k_{a p p}= & 0.0119 \ln \left(\left[\mathrm{H}_{2} \mathrm{O}_{2}\right]\right) \\
& -0.0316\end{aligned}$ & 0.86 \\
\hline $\mathrm{H}_{2} \mathrm{O}_{2}[\mu \mathrm{M}]$ & Pseudo-zero-order & $\mathrm{R}^{2}$ & Pseudo-first-order & $\mathrm{R}^{2}$ & Pseudo-second-order & $\mathrm{R}^{2}$ \\
\hline 163.0 & $\begin{aligned} k_{a p p}= & -0.022 \ln ([\mathrm{NaBr}]) \\
& +0.2095\end{aligned}$ & 0.99 & $\begin{aligned} k_{a p p}= & -0.034 \ln ([\mathrm{NaBr}]) \\
& +0.3240\end{aligned}$ & 0.99 & $\begin{aligned} k_{a p p}= & -0.055 \ln ([\mathrm{NaBr}]) \\
& +0.5448\end{aligned}$ & 0.99 \\
\hline 81.50 & $\begin{aligned} k_{a p p}= & -0.014 \ln ([\mathrm{NaBr}]) \\
& +0.1300\end{aligned}$ & 0.99 & $\begin{aligned} k_{a p p}= & -0.023 \ln ([\mathrm{NaBr}]) \\
& +0.2206\end{aligned}$ & 0.99 & $\begin{aligned} k_{a p p}= & -0.052 \ln ([\mathrm{NaBr}]) \\
& +0.4874\end{aligned}$ & 0.99 \\
\hline 40.75 & $\begin{aligned} k_{a p p}= & -0.008 \ln ([\mathrm{NaBr}]) \\
& +0.0761\end{aligned}$ & 0.99 & $\begin{aligned} k_{a p p}= & -0.013 \ln ([\mathrm{NaBr}]) \\
& +0.1237\end{aligned}$ & 0.99 & $\begin{aligned} k_{\text {app }}= & -0.024 \ln ([\mathrm{NaBr}]) \\
& +0.2277\end{aligned}$ & 0.99 \\
\hline 16.30 & $\begin{aligned} k_{a p p}= & -0.003 \ln ([\mathrm{NaBr}]) \\
& +0.0272\end{aligned}$ & 0.99 & $\begin{aligned} k_{a p p}= & -0.005 \ln ([\mathrm{NaBr}]) \\
& +0.0499\end{aligned}$ & 0.99 & $\begin{aligned} k_{a p p}= & -0.011 \ln ([\mathrm{NaBr}]) \\
& +0.1023\end{aligned}$ & 0.97 \\
\hline
\end{tabular}

\section{References}

1. Gracia-Lor, E.; Rousis, N.I.; Zuccato, E.; Bade, R.; Baz-Lomba, J.A.; Castrignanò, E.; Causanilles, A.; Hernández, F.; Kasprzyk-Hordern, B.; Kinyua, J.; et al. Estimation of caffeine intake from analysis of caffeine metabolites in wastewater. Sci. Total Environ. 2017, 609, 1582-1588. [CrossRef] [PubMed]

2. Dafouz, R.; Cáceres, N.; Rodríguez-Gil, J.L.; Mastroianni, N.; López de Alda, M.; Barceló, D.; de Miguel, Á.G.; Valcárcel, Y. Does the presence of caffeine in the marine environment represent an environmental risk? A regional and global study. Sci. Total Environ. 2018, 615, 632-642. [CrossRef] [PubMed]

3. Nödler, K.; Voutsa, D.; Licha, T. Polar organic micropollutants in the coastal environment of different marine systems. Mar. Pollut. Bull. 2014, 85, 50-59. [CrossRef] [PubMed]

4. Buerge, I.J.; Poiger, T.; Müller, M.D.; Buser, H.R. Caffeine, an anthropogenic marker for wastewater contamination of surface waters. Environ. Sci. Technol. 2003, 37, 691-700. [CrossRef]

5. Pearson, H. Caffeine tracks contamination. Nature 2003. [CrossRef]

6. Wu, X.; Ernst, F.; Conkle, J.L.; Gan, J. Comparative uptake and translocation of pharmaceutical and personal care products (PPCPs) by common vegetables. Environ. Int. 2013, 60, 15-22. [CrossRef]

7. Petrie, B.; Barden, R.; Kasprzyk-Hordern, B. A review on emerging contaminants in wastewaters and the environment: Current knowledge, understudied areas and recommendations for future monitoring. Water Res. 2015, 72, 3-27. [CrossRef]

8. Ebele, A.J.; Abou-Elwafa Abdallah, M.; Harrad, S. Pharmaceuticals and personal care products (PPCPs) in the freshwater aquatic environment. Emerg. Contam. 2017, 3, 1-16. [CrossRef]

9. Loos, R.; Carvalho, R.; Comero, S.; António, D.; Ghiani, M.; Lettieri, T.; Locoro, G.; Paracchini, B.; Tavazzi, S.; Gawlik, B. EU Wide Monitoring Survey on Waste Water Treatment Plant Effluents. Water Res. 2013, 47, 6475-6487. [CrossRef]

10. Sui, Q.; Huang, J.; Deng, S.; Yu, G.; Fan, Q. Occurrence and removal of pharmaceuticals, caffeine and DEET in wastewater treatment plants of Beijing, China. Water Res. 2010, 44, 417-426. [CrossRef]

11. Froehner, S.; Piccioni, W.; Machado, K.S.; Aisse, M.M. Removal capacity of caffeine, hormones, and bisphenol by aerobic and anaerobic sewage treatment. Water. Air Soil Pollut. 2011, 216, 463-471. [CrossRef]

12. Trovó, A.G.; Silva, T.F.S.; Gomes, O.; Machado, A.E.H.; Neto, W.B.; Muller, P.S.; Daniel, D. Degradation of caffeine by photo-Fenton process: Optimization of treatment conditions using experimental design. Chemosphere 2013, 90, 170-175. [CrossRef] [PubMed]

13. Glaze, W.H.; Kang, J.-W.; Chapin, D.H. The Chemistry of Water Treatment Processes Involving Ozone, Hydrogen Peroxide and Ultraviolet Radiation. Ozone Sci. Eng. 1987, 9, 335-352. [CrossRef]

14. Garrido-Cardenas, J.A.; Esteban-García, B.; Agüera, A.; Sánchez-Pérez, J.A.; Manzano-Agugliaro, F. Wastewater treatment by advanced oxidation process and their worldwide research trends. Int. J. Environ. Res. Public Health 2020, 17, 170. [CrossRef] 
15. Cuerda-correa, E.M.; Alexandre-franco, M.F.; Fern, C. Antibiotics from Water. An Overview. Water 2020, $12,1-50$.

16. Rytwo, G.; Klein, T.; Margalit, S.; Mor, O.; Naftaly, A.; Daskal, G. A continuous-flow device for photocatalytic degradation and full mineralization of priority pollutants in water. Desalin. Water Treat. 2015, 57, 16424-16434. [CrossRef]

17. Rytwo, G.; Daskal, G. A System for Treatment of Polluted Effluents 2016. U.S. Patent 15/512,516, 19 October 2017.

18. Oturan, M.A.; Aaron, J.-J. Advanced Oxidation Processes in Water/Wastewater Treatment: Principles and Applications. A Review. Crit. Rev. Environ. Sci. Technol. 2014, 44, 2577-2641. [CrossRef]

19. Deng, Y.; Zhao, R. Advanced Oxidation Processes (AOPs) in Wastewater Treatment. Curr. Pollut. Rep. 2015, 1, 167-176. [CrossRef]

20. Chong, M.N.; Jin, B.; Chow, C.W.K.; Saint, C. Recent developments in photocatalytic water treatment technology: A review. Water Res. 2010, 44, 2997-3027. [CrossRef]

21. Rendel, P.M.; Rytwo, G. Degradation kinetics of caffeine in water by $\mathrm{UV} / \mathrm{H}_{2} \mathrm{O}_{2}$ and $\mathrm{UV} / \mathrm{TiO} \mathrm{O}_{2}$. Desalin. Water Treat. 2020, 173, 231-242. [CrossRef]

22. Autin, O.; Hart, J.; Jarvis, P.; MacAdam, J.; Parsons, S.A.; Jefferson, B. The impact of background organic matter and alkalinity on the degradation of the pesticide metaldehyde by two advanced oxidation processes: $\mathrm{UV} / \mathrm{H}_{2} \mathrm{O}_{2}$ and $\mathrm{UV} / \mathrm{TiO}_{2}$. Water Res. 2013, 47, 2041-2049. [CrossRef] [PubMed]

23. Garcia-Muñoz, P.; Dachtler, W.; Altmayer, B.; Schulz, R.; Robert, D.; Seitz, F.; Rosenfeldt, R.; Keller, N. Reaction pathways, kinetics and toxicity assessment during the photocatalytic degradation of glyphosate and myclobutanil pesticides: Influence of the aqueous matrix. Chem. Eng. J. 2020, 384, 123315. [CrossRef]

24. Lanzafame, G.M.; Sarakha, M.; Fabbri, D.; Vione, D. Degradation of methyl 2-aminobenzoate (methyl anthranilate) by $\mathrm{H}_{2} \mathrm{O}_{2} / \mathrm{UV}$ : Effect of inorganic anions and derived radicals. Molecules 2017, 22, 619. [CrossRef] [PubMed]

25. Liao, C.H.; Kang, S.F.; Wu, F.A. Hydroxyl radical scavenging role of chloride and bicarbonate ions in the $\mathrm{H}_{2} \mathrm{O}_{2} / \mathrm{UV}$ process. Chemosphere 2001, 44, 1193-1200. [CrossRef]

26. Riga, A.; Soutsas, K.; Ntampegliotis, K.; Karayannis, V.; Papapolymerou, G. Effect of system parameters and of inorganic salts on the decolorization and degradation of Procion $\mathrm{H}$-exl dyes. Comparison of $\mathrm{H}_{2} \mathrm{O}_{2} / \mathrm{UV}$, Fenton, UV/Fenton, $\mathrm{TiO}_{2} / \mathrm{UV}$ and $\mathrm{TiO}_{2} / \mathrm{UV} / \mathrm{H}_{2} \mathrm{O}_{2}$ processes. Desalination 2007, 211, 72-86. [CrossRef]

27. Rioja, N.; Zorita, S.; Peñas, F.J. Effect of water matrix on photocatalytic degradation and general kinetic modeling. Appl. Catal. B Environ. 2016, 180,330-335. [CrossRef]

28. De Laat, J.; Truong Le, G.; Legube, B. A comparative study of the effects of chloride, sulfate and nitrate ions on the rates of decomposition of $\mathrm{H}_{2} \mathrm{O}_{2}$ and organic compounds by $\mathrm{Fe}(\mathrm{II}) / \mathrm{H}_{2} \mathrm{O}_{2}$ and $\mathrm{Fe}(\mathrm{III}) / \mathrm{H}_{2} \mathrm{O}_{2}$. Chemosphere 2004, 55, 715-723. [CrossRef] [PubMed]

29. Sharma, A.; Ahmad, J.; Flora, S.J.S. Application of advanced oxidation processes and toxicity assessment of transformation products. Environ. Res. 2018, 167, 223-233. [CrossRef] [PubMed]

30. Parkhurst, D.L.; Appelo, C.A.J. PHREEQC 2.14. 3 A computer program for speciation, batch-reaction, one-dimentional transport and inverse geochemical calculation. Water-Resour. Investig. Rep. 2007, 99, 4259.

31. Bray, W.C.; Livingston, R.S. The catalytic decomposition of hydrogen peroxide in a bromine-bromide solution, and a study of the steady state. J. Am. Chem. Soc. 1923, 45, 1251-1271. [CrossRef]

32. IUPAC. Compendium of Chemical Terminology: Gold Book. IUPAC Compend. Chem. Terminol. 2014, 1670.

(C) 2020 by the authors. Licensee MDPI, Basel, Switzerland. This article is an open access article distributed under the terms and conditions of the Creative Commons Attribution (CC BY) license (http://creativecommons.org/licenses/by/4.0/). 